\title{
THE CIRCADIAN CLOCK AND HUMAN ATHLETIC PERFORMANCE
}

\author{
BILJANA VITOŠEVIĆ ${ }^{*}$ \\ ${ }^{1}$ Faculty of Sport and Physical Education, Leposavić, University of Priština, Kosovska Mitrovica, Serbia
}

\begin{abstract}
The importance of circadian clock in managing of key muscle physiological processes, and therefore the impact on athletic performance is well studied. Specifically chronobiology examines the mechanisms of the biological clock and the consequences of disrupting its rhythm. Although a body of literature indicates that the peak performance of notable indicators of athletic performance exerts mainly in the afternoon and evening hours which is attributed to increased temperature of the body, certain variables such as vigilance, alertness and cognitive domains can influence the shift of the peak performance during the day. In addition, athletes face issues of desynchronization of their circadian rhythm during frequent transcontinental travels, since their performance is reduced and the adjustment of the biological clock requires some recommendations in the training process and behavioral approach. This review focuses on some current studies on endogenous and exogenous factors which affect the circadian rhythm in order to achieve better sport results, evaluation of the impact chronotype through chronometric tests and revising more valuable determinants of sport performance, as well as the application of new mathematical models in individual treatment of recovery of athletes in the phase of resynchronization.
\end{abstract}

Keywords: circadian clock, chronobiology, athletic performance, circadian disruption.

\section{INTRODUCTION}

That the man is indeed a part of nature and in a harmonious relationship with it, indicating the fact that although the biological rhythms are endogenous, they are adjusted to external stimuli. It has long been recognized that the circadian rhythm regulates many physiological processes, like secretion of hormones, sleep-wake cycle, body temperature and activity patterns. The term circadian rhythm is of Latin origin and means fluctuations set for a period of about 24 hours, or more precisely 24.5, which are synchronized with the cycle of light in the environment (Brown et al., 2005). That internal generator of rhythms, called "biological clock" is located in the suprachiasmatic nucleus (SCN) of the hypothalamus, which directly receives the information about light and the darkness through retinal-hypothalamic fibers. Information obtained from the outside are processed and through a central circadian clock sent to the other peripheral clocks of various tissues and cells whose work can be aligned or may be autonomous. The circadian synthesis and secretion of melatonin by the pineal gland is generated in the SCN and entrained primarily by the light-dark cycle (Cajochen et al., 2003). The molecular mechanism behind this cell-autonomous rhythm involve a complex network of negative transcription-translation-based feedback loop (Okamura et al., 2002). Many opposite research results are explained just with that powerful autonomy of peripheral clocks. These external signals or natural time synchronisers are in literature referred to as the German term "zeitgeber" and have the ability to "rewind" the biological clock

\footnotetext{
* Corresponding author: home.vitosevic@gmail.com
} BIOLOGY and thus can regulate circadian rhythms. Light as the leading zeitgeber, in addition to transmission along retinal-hypothalamic tract, also affects a number of other physiological rhythms, including plasma cortisol and plasma melatonin, which like its precursor serotonin plays an important role in the regulation of sleep (Carrier \& Monk, 2001). In addition to brightness, the timing of nutrition, physical activity and some social and psychological factors are also considered as zeitgebers and through the main biological clock, affect the peripheral oscillators that regulate many important physiological functions of metabolism. As the "gold standard" or key biological marker of human circadian rhythm is considered the temperature of the body which raises a number of physiological rhythms that manage an important metabolic variables (Wever, 1979).

The science that studies the mechanisms of biological clocks as well as the potential consequences of disrupting this system is referred to as chronobiology. A key component of this transdisciplinary science is the biological rhythm which is characterized by its frequency, period length, amplitude (acrophase-peak, mesor-mean and nadir-trough), as well as the phase (phase advance- shift to an earlier time or phase delayshift to a later time in the 24 hour cycle) of the particular parameter (Lee-Chiong, 2008). Another sphere of interest of chronobiologists is the clock mechanism and factors affecting the rhythm of the endogenous processes (Drust et al., 2005). Chronobiological systems are not isolated, but rather are associated with other irreversible homeostatic processes that define the metabolism (Reilly \& Waterhouse, 2009). Since the circadian changes are interrelated and synchronized with many external factors, there are a variety of scientific disciplines that study the coherence. Thus there is chrono-pharmacology that 
studies the optimal timing of medication, improving metabolic activity in respect of time of administration; chrono-nutrition that studies the relationship between the food and the the system of circadian rhythm; chrono-therapy in terms of medication in the coordination with the circadian rhythm in order to increase the effectiveness and reducing side effects (eg. corticosteroids in dosages that simulate adrenocortical cycle), and more recently sports-chronobiology, which examine the physical skills and their respective biochemical, physiological and psychological functions in a time frame. The main goal of these subdisciplines of chronobiology is to monitor the periodisation of sport trainings, particularly focusing on the adaptive mechanisms and timing in sports performance in terms of its optimization or elimination of desynchronisation factors (Jančokova et al., 2013).

\section{CIRCADIAN RHZTHM AND ATHLETIC PERFORMANCE}

In early publications, (Winget et al., 1985) pointed out the connection between circadian rhythm with many physiological functions associated with sports performance, such as motor and psychomotor skills, perceptual and cognitive functions. Biological rhythms are coordinated in accordance with the environment by adjusting the circadian clock primarily in relation to light, but also to physical activity. As mentioned, the main biological marker of human circadian rhythm is considered the temperature of the body. Increase in body temperature can increase the utilization of carbohydrates compared to fat as an energy source and eventually facilitate the actin and myosin mechanics in the musculoskeletal structures, which may result in improved physical performance through better skeletal muscle contractile properties (Starkie et al., 1999). A body of literature indicates that body core temperature is lowest in the morning around $04: 30 \mathrm{~h}$ and increases gradually during the day with acrophase around $18.00 \mathrm{~h}$ in the afternoon. Increased temperature in the afternoon is in line with the increased coordination, the highest reaction time, increasing muscle strength and cardiovascular efficiency (Atkinson \& Reilly, 1996; Shibata \& Tahara, 2014; Smolensky \& Lamberg, 2000). In addition, anaerobic power output and flexibility of joints are also the highest in the late afternoon (Racinais et al., 2005). But, when it comes to performance speeds, the best results were obtained between 08:30 $\mathrm{h}$ and 10:30h in the morning (Huguet et al., 1995). Reasons for the worse performance among athletes in the morning are associated with lower glycogen as a result of a night fasting, stiffness of joints after periods of rest and sleep, the less warming up the muscles in the morning compared to subsequent active period of the day and the fact that they are not yet sufficiently awake to keep their activity at a high level (Kline et al., 2007).

The heterogeneity in some studies and daily variations in the strength, power and force of skeletal muscle attributes to the peripheral clocks that possess temperature-dependent and temperature-independent mechanisms (Robinson et al., 2013) Many authors emphasize that although the temperature is the chief marker of sports performance, some variables such as the state of vigilance and alertness, and mood levels (which are the highest in the morning) can affect athletic performance (Atkinson \& Speirs, 1998; Reilly et al., 2003). Interestingly, simple mental actions such as reaction time are mainly associated with the core body temperature (neural activity and conduction, for example, increase with temperature) and they show a peak in the afternoon, while more complex mental actions that require cognitive and neuromuscular coordination, like, decision making, concentration and calculations show peak earlier, around noon. This data could be the reason for shifts peak sports performance in some studies (Valdez et al., 2008). Conducting of circadian rhythm in short-term (1 min or less) performance is controversial and can rely on the type of exercise and the muscle group tested (Bernard et al., 1998).

That the temperature associated with the functionality of skeletal muscles, (Taylor et al., 2011) are demonstrated by extending the active warm-up training session in the morning for $20 \mathrm{~min}$, and in the results achieved a reduction of the force and strength loss in the vertical jumps, which are obtained identical conditions of temperature in the afternoon training session. This result suggests that the protocol of warming-up in order to increase the temperature of the body could be helpful in reducing the diurnal difference in performance and improving performance especially in colder climates. Possible intercellular mechanisms include intercellular calcium and inorganic phosphate concentrations. For example, certain deviations from the traditional point of view of the relationship of the temperature of the body and sports performance is explained in the study of (Martin et al., 1999), by analyzing the role of circadian rhythm on the neural activation and the contractile ability of human adductor pollicis muscle. They found that the force during maximal voluntary contraction was higher in the evening than in the morning, with the increase in twitch and tetanus force, so they assume that peripheral mechanisms rather than central activation, have a predominant role in the diurnal fluctuation. The obtained results are attributable to the increase of calcium release from the sarcoplasmic reticulum, an increased sensitivity of calcium ion of contractile proteins actin and myosin and the changed-myosin ATPase activity. Subsequently, (Stephenson \& Williams, 1985) suggested that calcium concentration and temperature have a valuable effect on force at temperatures below $25^{\circ} \mathrm{C}$, with a decrease of interacting sites of the thin actin-myosin filament system, but little effect at temperatures above $25^{\circ} \mathrm{C}$. Indeed, this is confirmed in human studies, and it has been proven that there are fundamental thermodynamic differences in amplitude and sensitivity of the $\mathrm{Ca} 2+$, which further induces changes in protein binding, contraction and significant decline in force (Fitts, 2008). 
Another effect that can affect the diurnal variation, are the hormones testosterone and cortisol. Under normal conditions, the circadian profiles of testosterone and cortisol are very similar, with their peak early in the morning and a progressive decline during the day, and hence morning hours are less suitable for high catabolic activity of training (endurance and long running or resistance training with high repetition), therefore they are recommended in the late afternoon when the ratio $\mathrm{T} / \mathrm{C}$ is highest. In fact it is known that cortisol primarily affects the degradation of proteins, so its decline increased skeletal muscle hypertrophy through a reduction in the degradation of proteins (Hayes et al., 2012; Hayes et al., 2010). Much more work remains to be done in this area considering that both steroid hormones are very important for adaptation in the bouts of exercise. However, different types of exercise, their duration, intensity and recovery periods are parameters which often give different general results, so that consideration of some major conclusions are difficult to achieve. What is certain is that it is obvious that their influence is very important in neuromuscular function, in metabolic pathways, as well as to fluctuations in certain neurotransmitters (GABA, dopamine and serotonin) (Monti \& Jantos, 2008). So additional research with uniform conditions is required, with similar loadings in the sports performances and to be replicated in larger studies, by including more respondents.

Table 1. Summary of some findings in impact of circadian rhythm on performance

\begin{tabular}{|c|c|c|c|c|}
\hline Study & Mode & $\begin{array}{l}\text { Subjects, } \\
\text { Gender }\end{array}$ & Skills & Results \\
\hline Rahnama et al. (2009) & Soccer & $12, \mathrm{M}$ & Flexibility, socer skills & $\begin{array}{l}\text { The values were better in the evening than } \\
\text { morning }\end{array}$ \\
\hline Reilly et al. (2007) & Soccer & $8+8, \mathrm{M}$ & $\begin{array}{l}\text { Flexibility, reaction time, grip } \\
\text { strenght, football specific skills }\end{array}$ & $\begin{array}{l}\text { Peaks occurred between } 16: 00 \text { and 20:00 h, } \\
\text { daytime changes paralleled the temperature } \\
\text { rhythm }\end{array}$ \\
\hline Gharbi et al. (2013) & Soccer & $15, \mathrm{M}$ & Agility, dribbling, Coordination & $\begin{array}{l}\text { Higher at } 17,00 \mathrm{~h} \text {; No time-of-day effect was } \\
\text { observed for the coordination and skill index }\end{array}$ \\
\hline Chtourou et al. (2013) & Soccer & $20, \mathrm{M}$ & Vertical jump height (SJ, CMJ) & Lower morning values in vertical jump height \\
\hline Atkinson et al. (2005) & Cycling & $8, \mathrm{M}$ & Power output & $\begin{array}{l}16.1-\mathrm{km} \text { cycling performance is worse in the } \\
\text { morning than in the afternoon, even they perform } \\
\text { a vigorous } 25 \text {-min warm-up }\end{array}$ \\
\hline Souissi et al. (2012) & Cycling & $22, \mathrm{M}$ & $\begin{array}{l}\text { Wingate tests (muscle power), } \\
\text { mean-power-frequency (MPF), } \\
\text { Neuromuscular efficiency } \\
\text { (NME) }\end{array}$ & $\begin{array}{l}\text { MPF and NME are higher in the evening during } \\
\text { the Wingate cycling test and the evening } \\
\text { improvement in muscle power and fatigue is due } \\
\text { to an enhancement of muscle contract. Propertis }\end{array}$ \\
\hline Rai \& Tiwari, (2015) & Volleyball & $30, \mathrm{M}$ & $\begin{array}{l}\text { Agility, explosive strenght, } \\
\text { speed ability }\end{array}$ & $\begin{array}{l}\text { Diurnal variation does not affect the performance } \\
\text { of volleyball players on selected motor fitness } \\
\text { components }\end{array}$ \\
\hline Souissi et al. (2013) & Judo & $12, \mathrm{M}$ & Wingate tests & $\begin{array}{l}\text { Muscle power and strength were significantly } \\
\text { higher at 16:00 than 09:00 hours }(p<0.05)\end{array}$ \\
\hline Jarraya et al. (2014) & $\begin{array}{l}\text { Handball's } \\
\text { goalkeeper }\end{array}$ & $12, \mathrm{M}$ & Cognitive tasks & $\begin{array}{c}\text { Significantly higher at evening; } \\
\text { Cognitive performances of GK are time-of-day- } \\
\text { dependent with the highest values observed in } \\
\text { the morning }\end{array}$ \\
\hline
\end{tabular}

In addition, different results in peak athletic performance may be the result of inter-individual variation in circadian rhythmicity. Morning- and evening-type (an early "lark" or a late "owl") endogenously individuals differ in the circadian phase of their biological clocks. Sometimes these chronotypes cope better with the training sessions at different times of the day (Kerkhof 
et al., 1996). In recent times, new research focuses on the chronometric tests as novel approach, which is based on the fact that the main predictor of peak performance is actually time since entrained awakening, and not time of day. A recent study of (Facer-Childs \& Brandstaetter, 2015) with the participation of 121 athletes competitors, showed that the time of the entrained awakening reflects the internal biological clock, and varies by about $26 \%$ compared to the real time of day. Consequently, these differences entail the different physiology, such as different levels of cortisol and melatonin. These studies have provided important insights into peak performance between circadian phenotypes in real time and in a time of awakening, which can be used to better optimize performance. They concluded that it does not matter in which time of the day is the best performance of a person, but how many hours after waking up is a performance or competition carried out.

Some studies of sports performance and their different skills in relation to the time of day, are summarized in Table 1. Most of results have shown a better value in the afternoon and evening which is coherent with some general viewpoint in line with circadian rhythm. By contrast, (Rai \& Tiwari, 2015) did not observe that diurnal variations have an impact on performance of volleyball players in selected motor fitness. Similarly, cognitive performance of handball goalkeepers showed the highest values in the morning, which is desynchronized from rhythm of core temperature, but are in accordance with some opinion that fatigue occurs later in the day (Jarraya et al., 2014).

\section{MECHANISMS OF MOLECULAR BACKGROUND}

As it is known, SCN achieves it regulatory role directly, by nervous and humoral paths, and indirectly, through the body temperature, physical activity or feeding rhythms. However, regulation of the individual cell type or organ is usually complex and involves multiple pathways. The largest number of efferent pathways from the SCN includes neurotransmitters that enable endocrine responses. Through various endocrine hormone target tissues are then prepared for certain changes. Glucocorticoids, whose rhythm is regulated by these pathways, are extremely important to reset or synchronize many peripheral clocks in the body (Dickmeis, 2009; Chung et al., 2011). It is known that GABAergic neurons are responsible for the inhibitory effect of SCN on the secretion of melatonin during the day, while glutamatergic neurons stimulate the release of melatonin at night. Melatonin, as well as glucocorticoids, however, has a regulatory role in the circadian activity of many tissues (Kalsbeek et al., 2006; Hirota \& Fukada, 2004). Each of these hormones acting on receptors in various tissues, and therefore transmitted a message to the target tissue.

Molecular clock of mammals consisting of a primary loop comprising the basic clock genes (core clock genes) and additional, regulatory loop, which altogether gives a complex network of negative feedback loops. The availability and activity of the protein clocks regulates at post-transcriptional and posttranslational level. The main positive regulators or activators of these loops are CLOCK (Circadian Locomotor Output Cycles Kaput) and BMAL1 (Brain and Muscle Arnt-like 1) and the other two are repressors (PER-Period 1, 2 and 3), and CRYCryptochrome 1 and 2), with a set of kinases and phosphatases as adjusters and stabilizers (Partch et al, 2014). But what initiates and drives all the action between SCN, neuronal networks, neurotransmitter release to cellular functions and coordinate their work at the intracellular level, are calcium ions $(\mathrm{Ca} 2+)$, because once they enter the cytosol, they exert different effects on proteins and coordinates numerous cell functions (Enoki et al., 2017). The research done by shutting down the input pathway by tetrodotoxin (TTX) reduces the amplitude of $\mathrm{Ca} 2+$ rhythms by approximately $30 \%$, assuming that intracellular $\mathrm{Ca} 2+$ levels are managed by both input pathways to the core loop and output pathways from the loop to diverse cellular functions (Enoki et al., 2012). All this indicates not only the importance of the role of calcium ions, but also the synchronization and correlation of all these components because disruption of one factor destabilizes the entire system. Although most of the data comes from experimental work with animal, humans appear to have a similar set and mechanisms of clock genes (Cermakian \& Boivin, 2003). Accordingly, some studies have shown that different types, intensity and duration of exercise may affect different transcriptional output of the biological clock. A study by (Zambon et al., 2003) found that resistance exercise may alter the expression of circadian clock regulatory genes in human skeletal muscle. These findings are important because they support the view that sometimes peripheral clocks are independent in their regulation of SCN. But the specific mechanisms of regulation of individual genes of oscillators and their expression in the different loads in exercise, and their behavior in different time spans, remains unclear. Also, the independence of the peripheral clock with respect to SCN is not always determined, which remains an unexplored area and requires further investigation.

\section{DESYNCHRONIZATION OF CIRCADIAN RHYTHM}

The change of external factors, such as changes in the cycle of light and darkness at the trans-continental flights or work shift, can result in desynchronization of circadian rhythm. Adaptation to change, as well as resynchronization are individual, requiring several days and takes place in stages. Jet leg is transient disturbance occurring by desynchronization of steady physiological and biological rhythms. It manifests itself on travelling where the flight passes through the three or more time zones to the final destination. The first phase of desynchronization can be accompanied by symptoms such as fatigue, headache, nausea, decrease of concentration, insomnia, but as the organism adjusts the biological clock to a new time zone, these symptoms slowly disappear (phase of 
resynchronization). Adaptation to changes in circadian rhythms are individual, so that younger adapt faster than elderly. It was established that for every time zone crossed, one day is required to restore normal rhythm. Crossing over six time zones requires about two days up to two weeks. Faster adaptation is present in flying to the west because it extends the day and gets more time compared to those flying to the east. During the adjustment period of the biological clock to a new time zone, physical performance may be impaired because it maintains the parallelism with the temperature of the body and the biological clock and is not adequately prepared for the new destination. In addition, the mental performance may be reduced and further exacerbated by insomnia (Waterhouse et al., 2001). (Lemmer et al., 2001) suggests that elite athletes travelling to the west or east destinations over six to eight time zones demonstrated modified grip strenght and weak performance in training sessions or several days after the flight.

While the biological clock is adjusted and completely remodeled, it is recommended to establish the normal daily behavior, exposure to sunlight, rhythm activities, rest, taking a meal, waking and sleep in relation to the local time in order to normalize biological rhythms as soon as possible. The type of food and timing of meals are also important aspects in the adaptation to a shifted zone. It is known that high-protein food stimulates an adrenaline path that increases alertness and readiness, so it is recommended for breakfast, but foods rich in carbohydrates increases the secretion of insulin, which facilitates the uptake of tryptophan, an essential amino acid which is then converted into serotonin, and promotes drowsiness, so this kind of food is recommended in the evening. Adequate hydration is implied because it eliminates fatigue that often accompanies jet leg (Reilly et al., 2007c; Reilly et al., 2007).

With regard to the important sports events, quality assurance of sports performance requires serious planning of travelling. Thus it is recommended previous training in the time that is in line with the future time zone, as well as planning the arrival earlier and thus adequate adaptation. Behavioral approach involves timing and intensity of training, and gradual build-up of the level of training (without strenuous and risky exercise in the initial sessions in order to avoid possible injuries). Food timing is certainly a better approach than pharmacological, but not should be avoided supplementation and maintaining sleep through low dose of melatonin, bearing in mind the direction and purpose of adjusting the biological clock, as some side effects of melatonin (headache, dizziness, morning drowsiness). Alternative therapies recommended as antidotes for jet-lag comprise homeopathic remedies, massage and relaxation are without any evidence of their effectiveness (Reilly et al., 2007). There is little evidence based on for re-timer eyeglasses that emit green light, which is supposed to mimic natural sunlight and is believed to help reset the biological clock.
The idea of mathematical models of performance is not new, but has previously relied on the different models, the first one implying that the homeostatic and circadian processes are independent and additive and others who implies their interaction (Carrier \& Monk, 2000). Other types of models have studied the dynamics of the SCN, both the main pacemaker and peripheral oscillators and trying to numerically determine the behavior. The latest model conceived by (Lu et al., 2016) unified the dynamics of many individual oscillators and held them up to the macroscopic level. The advantage of this model, according to the authors, is its simplicity compared to previous models, ease of interpretation and applicability. As base they used sinusoidally forced Kuramoto model from animal experiments (direct measurements of SCN oscillators are not available for humans but is used as an indirect deduction), and added external parameters such as the sensitivity of an individual's response to sunlight, cloud distribution, geographical latitude, and seasonality. This is the most actual model and its value consists of the facts that may help explain how eastward and westward travel can have different effects on the individual recovery of circadian rhythms. They suggest further research in the field of resynchronization including a more realistic approach of the oscillators and better analysis of SCN complex network.

\section{CONCLUSION}

Interpretation of sports chronobiology is based on the premise that the fusion of endogenous and exogenous mechanisms has a strong influence on the circadian rhythm in sports performance. In addition to light, physical activity is important zeitgeber that through the main biological clock operates on the peripheral oscillators, and then they initiate a myriad of physiological functions that raise hormones, enzymes and neurotransmitters, and through a complex network of negative feedback loops can define the response and adaptation of the organism. That response, although tightly bound to the internal biological clock, may shift its limits in relation to environmental conditions. This space represents a major enigma for scientists, although it is being explored for a long time now. Most of the borders of peak performance in physical skills are generally known. Physical skills such as strength, agility and flexibility has its peak in the afternoon and evening, which is associated with an increase in temperature as the main marker of biological rhythms. However, many other variables such as vigilance, alertness and cognitive abilities may affect the outcome of the performance and display fine alterations. This shift is explained by the influence of the peripheral clocks, but also by numerous other factors, endogenous (different chronotype) or exogenous (different environmental conditions, methodology of research). Some new approaches to the evaluation of circadian rhythms deserve great attention and suggest correction of analysis regarding the peak performance of the day and propose that circadian phenotypes are also taken into 
considerations and performance inquiry as a function of time since awakening.

On the other hand, often cited that the biggest enemy of athletes is the syndrome of jet lag, considering the frequent transcontinental travells. Although the response and adaptation in athletes are individual, sometimes these circadian disruptions may affect the reduction in athletes performance. This requires serious prior preparation for travel, training and time of food intake in order to minimize these issues. Recently, a lot of attention is devoted to the application of mathematical models that can individually calculate the required recovery in distant eastward and westward journeys, which translated into practice can be of great help to athletes in the phase of resynchronization.

\section{REFERENCES}

Atkinson, G., \& Reilly, T. 1996. Circadian variation in sports performance. Sports Med, 21(4), pp. 292-312. pmid:8726347. doi:10.2165/00007256-199621040-00005

Atkinson, G., \& Speirs, L. 1998. Diurnal variation in tennis service. Percept Mot Skills, 86(3 Pt 2), pp. 1335-8. pmid:9700810

Atkinson, G., Todd, C., Reilly, T., \& Waterhouse, J. 2005. Diurnal variation in cycling performance: Influence of warmup. J Sports Sci, 23(3), pp. 321-9. pmid:15966350. doi:10.1080/02640410410001729919

Bernard, T., Giacomoni, M., Gavarry, O., Seymat, M., \& Falgairette, G. 1998. Time-of-day effects in maximal anaerobic leg excercise. Eur. J. Appl. Physiol, 77(3), pp. 133138. pmid: 9459533

Brown, S.A., Fleury-Olela, F., Nagoshi, E., Hauser, C., Juge, C., Meier, C.A., . . . Schibler, U. 2005. The period length of fibroblast circadian gene expression varies widely among human individuals. PLoS Biol., 3(10), p. 338. pmid:16167846. doi:10.1371/journal.pbio.0030338

Cajochen, C., Kräuchi, K., \& Wirz-Justice, A. 2003. Role of melatonin in the regulation of human circadian rhythms and sleep. J. Neuroendocrinol., 15(4), pp. 432-7. pmid:12622846

Carrier, J., \& Monk, T.H. 2000. Circadian rhythms of performance: New trends. Chronobiol. Int., 17(6), pp. 71932. pmid:11128289

Cermakian, N., \& Boivin, D.B. 2003. A molecular perspective of human circadian rhythm disorders. Brain Research Reviews, 42, pp. 204-220. pmid:12791440

Chtourou, H., Aloui, A., Hammouda, O., Chaouachi, A., Chamari, K., \& Souissi, N. 2013. Effect of static and dynamic stretching on the diurnal variations of jump performance in soccer players. PLoS ONE, 8(8), p. 70534. pmid:23940589. doi:10.1371/journal.pone.0070534

Chung, S., Son, G.H., \& Kim, K. 2011. Circadian rhythm of adrenal glucocorticoid: Its regulation and clinical implications. Biochim. Biophys. Acta, 1812(5), pp. 581-91. pmid:21320597. doi:10.1016/j.bbadis.2011.02.003

Dickmeis, T. 2009. Glucocorticoids and the circadian clock. J. Endocrinol, 200(1), p. 322. doi:10.1677/JOE-08-0415

Drust, B., Waterhouse, J., Atkinson, G., Edwards, B., \& Reilly, T. 2005. Circadian rhythms in sports performance: An update. Chronobiol. Int., 22(1), pp. 21-44. pmid:15865319. doi:10.1081/CBI-200041039

Enoki, R., Kuroda, S., Ono, D., Hasan, M.T., Ueda, T., Honma, S., \& Honma, K. 2012. Topological specificity and hierarchical network of the circadian calcium rhythm in the suprachiasmatic nucleus. Proc. Natl. Acad. Sci USA, 109(52), pp. 21498-21503. doi:10.1073/pnas. 1214415110

Enoki, R., Ono, D., Kuroda, S., Honma, S., \& Honma, K. 2017. Dual origins of the intracellular circadian calcium rhythm in the suprachiasmatic nucleus. Sci. Rep., 7, p. 41733. doi:10.1038/srep41733

Facer-Childs, E., \& Brandstaetter, R. 2015. The impact of circadian phenotype and time since awakening on diurnal performance in athletes. Current biology , 25(4), pp. 518-22. pmid:25639241. doi:10.1016/j.cub.2014.12.036

Fitts, R.H. 2008. The cross-bridge cycle and skeletal muscle fatigue. J. Appl. Physiol., 104(2), pp. 551-8. pmid:18162480. doi:10.1152/japplphysiol.01200.2007

Gharbi, A., Masmoudi, L., Ghorbel, S., Noureddine, B., Maalej, R., Tabka, Z., \& Zaouali, M. 2013. Time of Day Effect on Soccer-Specific Field Tests in Tunisian Boy Players. Advances in Physical Education, 3(2), pp. 71-75. doi:10.4236/ape.2013.32011

Hayes, L.D., Bickerstaff, G.F., \& Baker, J.S. 2010. Interactions of cortisol, testosterone, and resistance training: Influence of circadian rhythms. Chronobiol. Int., 27(4), pp. 675-705. pmid:20560706. doi:10.3109/07420521003778773

Hayes, L.D., Grace, F.M., Kilgore, J.L., Young, J.D., \& Baker, J.S. 2012. Diurnal variation of cortisol, testosterone and their ratio in apparently healthy males. Sport SPA, 9(1), pp. 5-13.

Huguet, G., Touitou, Y., \& Reinberg, A. 1995. Diurnal changes in sport performance of 9- to 11year-old school children. Chronobiol Intl., 12, pp. 351-362.

Jančokova, L. 2013. Chronobiology from theory to sports practice.Krakow: Towarzystwo Slowakow w Posce., p. 30 Monograph ed.

Jarraya, S., Jarraya, M., Chtourou, H., \& Souissi, N. 2014. Diurnal variations on cognitive performance in handball goalkeepers. Biological Rhythm Research, 45(1), pp. 93-101. doi:10.1080/09291016.2013.811032

Kalsbeek, A., Palm, I.F., La, F.S.E., Scheer, F.A.J.L., PerreauLenz, S., Ruiter, M., . . . Buijs, R.M. 2006. SCN outputs and the hypothalamic balance of life. J. Biol. Rhythms, 21(6), pp. 458-69. pmid:17107936. doi:10.1177/0748730406293854

Kerkhof, G.A., \& van Dongen, H.P.A. 1996. Morning-type and evening-type individuals differ in the phase position of their endogenous circadian oscillator. Neurosci Lett, 218, pp. 153 156.

Kline, C.E., Durstine, L.J., Davis, M.J., Moore, T.A., Devlin, T.M., Zielinski, M.R., \& Youngstedt, S.D. 2007. Circadian variation in swim performance. J. Appl. Physiol., 102(2), pp. 641-9. pmid:17095634. doi:10.1152/japplphysiol.00910.2006

Lee-Chiong, T.L. 2008. Sleep medicine: Essentials and review. In .Oxford - New York: Oxford University Press. ISBN-13: 978-0195306590.

Lemmer, B., Kern, R., Nold, G., \& Lohrer, H. 2002. Jet lag in athletes after eastward and westward time-zone transition. Chronobiol. Int., 19(4), pp. 743-64. pmid:12182501 
Lu, Z., Klein-Cardeña, K., Lee, S., Antonsen, T.M., Girvan, M., \& Ott, E. 2016. Resynchronization of circadian oscillators and the east-west asymmetry of jet-lag. Chaos, 26(9), p. 94811. pmid:27781473. doi:10.1063/1.4954275

Martin, A., Carpentier, A., Guissard, N., van Hoecke, J., \& Duchateau, J. 1999. Effect of time of day on force variation in a human muscle. Muscle Nerve, 22(10), pp. 1380-7. pmid:10487904. doi:10.1002/(SICI)10974598(199910)22:10<1380::AID-MUS7>3.0.CO;2-U

Okamura, H., Yamaguchi, S., \& Yagita, K. 2002. Molecular machinery of the circadian clock in mammals. Cell Tissue Res., 309, pp. 47-56. doi:10.1007/s00441-002-0572-5

Partch, C.L., Green, C.B., \& Takahashi, J.S. 2014. Molecular architecture of the mammalian circadian clock. Trends Cell Biol., 24(2), pp. 90-9. pmid:23916625. doi:10.1016/j.tcb.2013.07.002

Racinais, S., Blonc, S., Jonville, S., \& Hue, O. 2005. Time of day influences the environmental effects on muscle force and contractility. Med Sci Sports Exerc, 37(2), pp. 256-61. pmid:15692321. doi:10.1249/01.MSS.0000149885.82163.9F

Rahnama, N., Sajjadi, N., Bambaeichi, E., Sadeghipour, H.R., Daneshjoo, H., \& Nazar, B. 2009. Diurnal Variation on the Performance of Soccer-Specific Skills. World Journal of Sport Sciences, 2(1), pp. 27-30.

Rai, V., \& Tiwari, L.M. 2015. Diurnal variation on the performance of selected motor fitness components of volleyball Players. International Journal of Physical Education, Sports and Health, 2(2), pp. 86-88.

Reilly, T., Atkinson, G., Edwards, B., \& et al., 2007. Coping with jet-lag: A position statement for the European College of Sport Science. Eur J Sport Sci., 7, pp. 1-7. doi:10.1080/17461390701216823

Reilly, T., Waterhouse, J., Burke, L.M., \& Alonso, J.M. 2007. Nutrition for travel. Journal of Sports Sciences, 25(1), pp. 125-134. doi:10.1080/02640410701607445

Reilly, T., \& Waterhouse, J. 2009. Chronobiology and Exercise. Medicina Sportiva, 13(1), pp. 54-60.

Reilly, T., Atkinson, G., Edwards, B., Waterhouse, J., Farrelly, K., \& Fairhurst, E. 2007. Diurnal variation in temperature, mental and physical performance, and tasks specifically related to football (soccer). Chronobiol. Int., 24(3), pp. 50719. pmid:17612948. doi:10.1080/07420520701420709

Reilly, T., Farrelly, K., Edwards, B., \& Watehouse, J. 2003. Time of day and performance test in male Football players. Book of abstracts. . In: The 5th Word Congress of Science and Football Portugal. , pp. 268-270

Robinson, W.R., Pullinger, S.A., Kerry, J.W., Giacomoni, M., Robertson, C.M., Burniston, J.G., . . . Edwards, B.J. 2013. Does lowering evening rectal temperature to morning levels offset the diurnal variation in muscle force production?. Chronobiol. Int., 30(8), pp. 998-1010. pmid:23863092. doi:10.3109/07420528.2012.741174

Shibata, S., \& Tahara, Y. 2014. Circadian rhythm and exercise. The Journal of Physical Fitness and Sports Medicine, 3(1), pp. 65-72. doi:10.7600/jpfsm.3.65

Smolensky, M., \& Lamberg, L. 2000. The Body Clock Guide to Better Health: How to Use your Body's Natural Clock to Fight Illness and Achieve Maximum Health, 1st ed.New York: Henry Holt and Co..

Souissi, H., Chtourou, H., Chaouachi, A., Chamari, K., Souissi, N., \& Amri, M. 2012. Time-of-day effects on EMG parameters during the Wingate test in boys. J Sports Sci Med., 11, pp. 380-386. PMC3737921. pmid:24149343

Souissi, N., Chtourou, H., Aloui, A., Hammouda, O., Dogui, M., Chaouachi, A., \& Chamari, K. 2013. Effects of Time-of-Day and Partial Sleep Deprivation on Short-Term Maximal Performances of Judo Competitors. Journal of Strength \& Conditioning Research, 27(9), pp. 2473-2480. doi:10.1519/JSC.0b013e31827f4792

Starkie, R.L., Hargreaves, M., Lambert, D.L., Proietto, J., \& Febbraio, M.A. 1999. Effect of temperature on muscle metabolism during submaximal exercise in humans. Exp. Physiol., 84(4), pp. 775-84. pmid:10481233

Stephenson, D.G., \& Williams.D.A., 1985. Temperaturedependent calcium sensitivity changes in skinned muscle fibres of the rat and toad. Journal of Physiology, 360, pp. 112.

Taylor, K., Cronin, J.B., Gill, N., Chapman, D.W., \& Sheppard, J.M. 2011. Warm-up affects diurnal variation in power output. Int J Sports Med, 32(3), pp. 185-9. pmid:21305444. doi:10.1055/s-0030-1268437

Valdez, P., Reilly, T., \& Waterhouse, J. 2008. Rhythms of Mental Performance. Mind, Brain, and Education, 2(1), pp. 7-16. doi:10.1111/j.1751-228X.2008.00023.x

Zambon, A.C., McDearmon, E.L., Salomonis, N., Vranizan, K.M., Johansen, K.L., Adey, D., . . . Conklin, B.R. 2003. Time- and exercise-dependent gene regulation in human skeletal muscle. Genome Biol., 4(10), p. 61. pmid:14519196. doi:10.1186/gb-2003-4-10-r61

Waterhouse, J., Minors, D., Akerstedt, T., \& et. al., 2001. Rhythms of human performance. In J. Takahashi, F. Turek, \& R. Moore Eds., Handbook of behavioral neurobiology: Circadian clocks.New York: Kluver Academic/Plenum Publishers., pp. 571-601.

Wever, R.A. 1979. The circadian system of man: Results of experiments under temporal isolation.New York: SpringerVerlag.

Winget, C.M., DeRoshia, C.W., \& Holley, D.C. 1985. Circadian rhythms and athletic performance. Med Sci Sports Exerc, 17(5), pp. 498-516. pmid:3906341 